\title{
Numerical Simulation on Heat Pipe Heat Exchanger: Effects of Different Wind Speeds
}

\author{
Bing Xia, Yebin Yin, Jinghong Lian, Guang Yang, Guoyou Xu, Xiang Gou, \\ Enyu Wang, Liansheng Liu, Jinxiang Wu
}

School of Energy and Environmental Engineering, Hebei University of Technology, Tianjin 300401, China

${ }^{a}$ Corresponding author email: gouxiang@sina.com

Keywords: Heat pipe; Ventilation; Numerical simulation; Heat exchanger

\begin{abstract}
The heat pipe heat exchanger is applied widely with the advantages of low investment, small volume and good effect of heat transfer. To make a full and reasonable use of the heat resource, a heat pipe heat exchanger is introduced in this paper. Numerical simulation of the heat pipe heat exchanger with different wind speeds is carried out by the CFD software FLUENT. The temperature, velocity contours and effects of heat transfer were compared in different wind speed conditions such as $0.02 \mathrm{~m} / \mathrm{s}, 0.04 \mathrm{~m} / \mathrm{s}, 0.06 \mathrm{~m} / \mathrm{s}, 0.08 \mathrm{~mm} / \mathrm{s}, 0.1 \mathrm{~m} / \mathrm{s}$ and $0.12 \mathrm{~m} / \mathrm{s}$. The maximum difference of cold and hot air heat flow rate is $5.344 \mathrm{~W}$ in the air velocity of $0.04 \mathrm{~m} / \mathrm{s}$. And the results show that rate of heat recovery can reach $52.9 \%$ in this model.
\end{abstract}

\section{Introduction}

Heat pipe is a kind of heat transfer element with high efficiency, which can be realized by the phase change and continuous working fluid. The equivalent thermal conductivity of heat pipe can reach $10^{3} \sim 10^{4}$ times of metal[1-3].In numerous ways of heat recovery, by the high efficient heat transfer component heat pipe consisting of a heat pipe heat exchanger has simple structure, less material consumption, high heat transfer efficiency, low pressure loss and power consumption advantages, is being more and more widely application [4-6].In daily life, to improve indoor air quality through ventilation will increase the indoor cold (hot) heat loads and energy consumption[79].If the heat exchanger is applied to the ventilation of the room, it can improve the indoor air quality, also greatly reduce the indoor heat loads and energy consumption. Based on the advantages of heat pipe heat exchanger, the numerical simulation of various operating conditions on the basis of the software FLUENT is carried out. Study on the efficiency of heat transfer characteristics and distribution of temperature and velocity of heat exchanger, in order to guide the optimization and improvement of the heat pipe ventilation heat exchanger [10-12].

\section{Model design and establishment}

Fig.1. shows the three-dimensional model which made by gambit software. Model has two channels of cold air and hot air flow respectively. Indoor parts include cold air inlet and hot air outlet, and cold air outlet and hot air inlet to the outdoor part. Model design size is $550 \mathrm{~mm} \times 300 \mathrm{~mm} \times 100 \mathrm{~mm}$, which includes $12 \varphi 8$ heat pipe .Heat pipes through the hot and cold air flow between the two channels and maintain a triangular arrangement of cross row. The fins of adjacent rows staggered to keep uniform distribution. Heat pipes and fins are arranged into the fluid solid coupling wall surface and the heat pipe is arranged for solid region especially. In order to ensure the accuracy of the calculation of the internal heat pipe and fins are carried out the grid encryption and the final grids are divided into 620 thousands. 


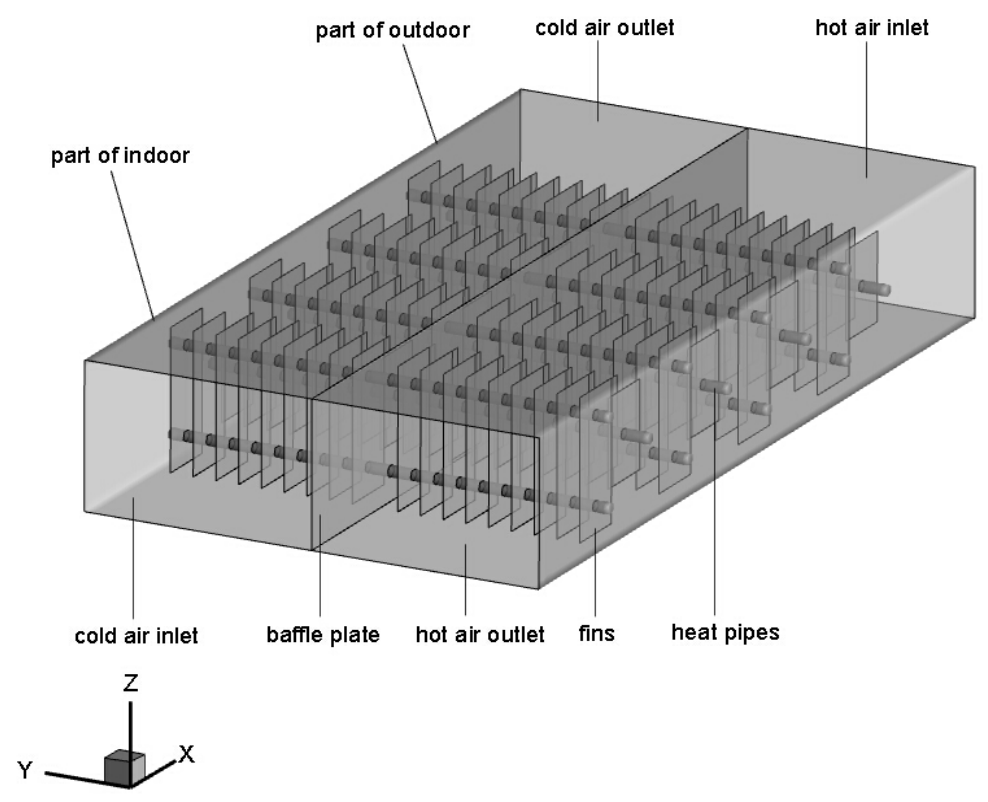

Fig.1.Three-dimensional model diagram of heat pipe heat exchanger

The simulation is based on unsteady, implicit solution based on pressure. Standard k-epsilon turbulence model is used in this model. Cold and hot air inlet are both provided with boundary conditions for velocity inlet boundary conditions. There are six groups of different air velocity conditions include $0.02 \mathrm{~m} / \mathrm{s}, 0.04 \mathrm{~m} / \mathrm{s}, 0.06 \mathrm{~m} / \mathrm{s}, 0.08 \mathrm{~m} / \mathrm{s}, 0.1 \mathrm{~m} / \mathrm{s}$ and $0.12 \mathrm{~m} / \mathrm{s}$. Cold air inlet temperature is $299 \mathrm{~K}$, and hot air inlet temperature sets $313 \mathrm{~K}$.The outlet is set to pressure outlet boundary conditions. After about 20 thousands iterations of the residual error, the accuracy requirements are achieved.

\section{Simulation results and analysis}
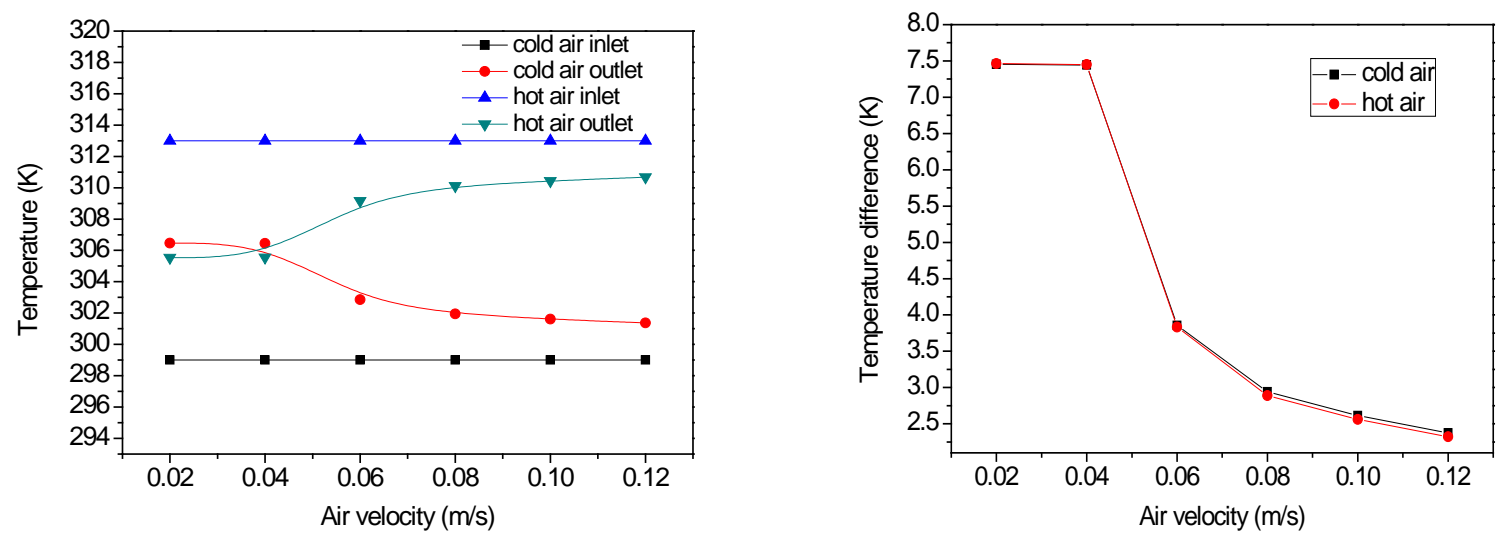

Fig.2.The average temperature and temperature difference of the air inlet and outlet

Fig.2.shows the difference in temperature between cold and hot air inlet and outlet at both $0.02 \mathrm{~m} / \mathrm{s}$ and $0.04 \mathrm{~m} / \mathrm{s}$ is the largest, and it can reach about $7.44 \mathrm{~K}$. With the air velocity increases, temperature decreases gradually, while the cold air temperature compared with hot air temperature rising value reduces the gap between the minimum value. With the increasing of air velocity, the temperature difference is also increased. 

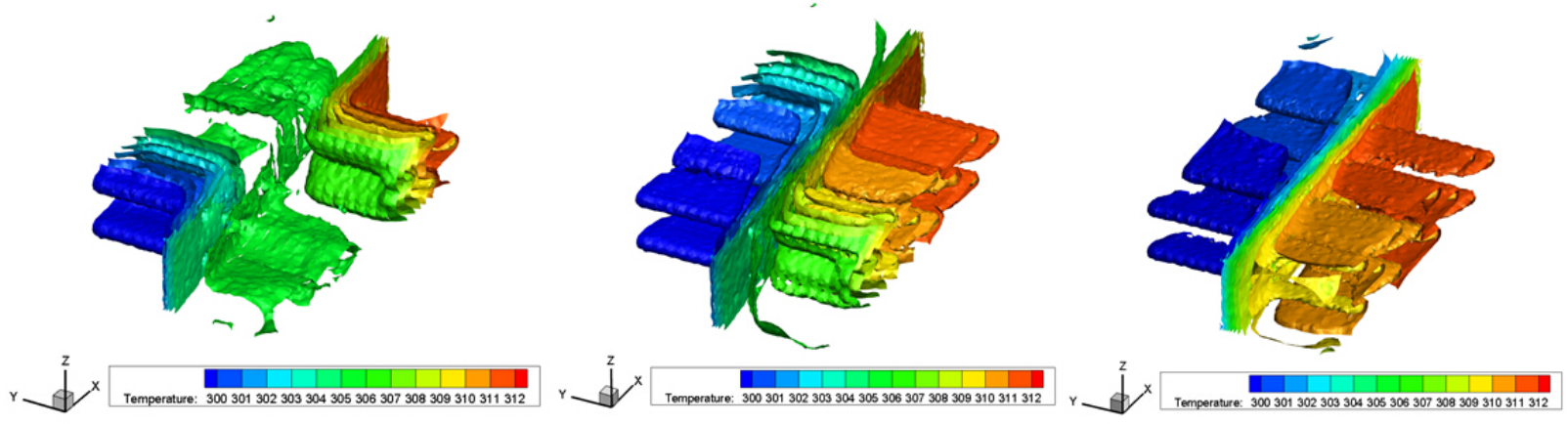

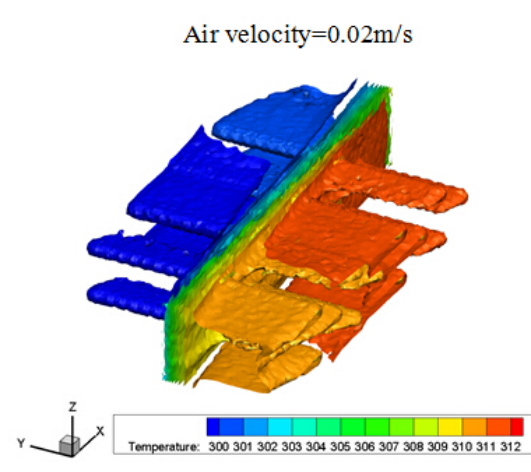

Air velocity $=0.08 \mathrm{~m} / \mathrm{s}$

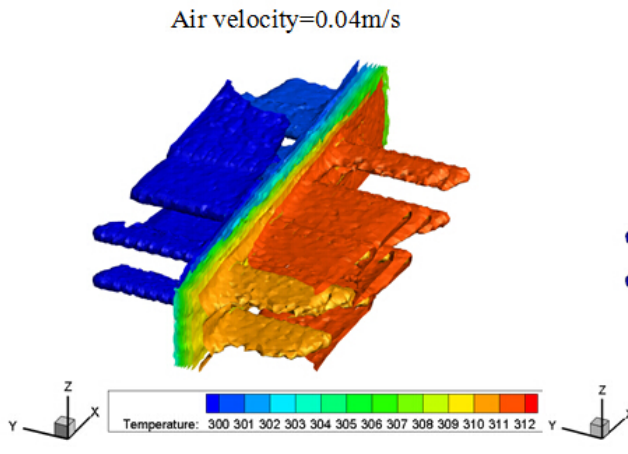

Air velocity $=0.1 \mathrm{~m} / \mathrm{s}$

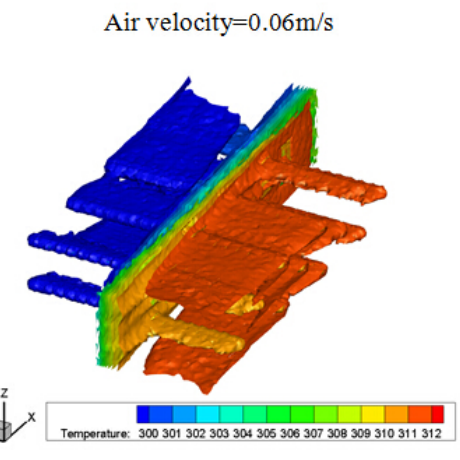

Air velocity $=0.12 \mathrm{~m} / \mathrm{s}$

Fig.3.Isothermal surface at different air velocity
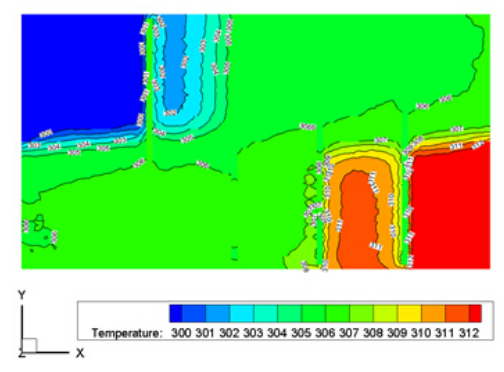

Air velocity $=0.02 \mathrm{~m} / \mathrm{s}$

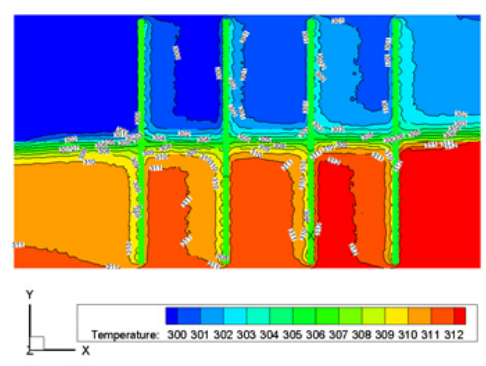

Air velocity $=0.08 \mathrm{~m} / \mathrm{s}$
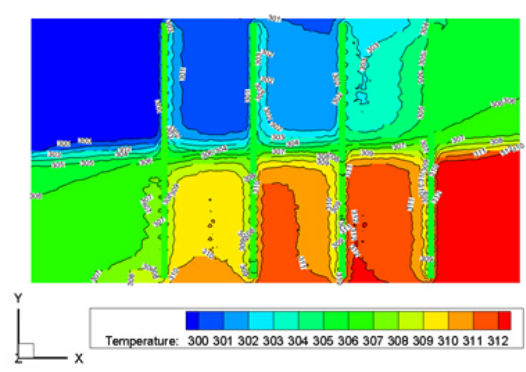

Air velocity $=0.04 \mathrm{~m} / \mathrm{s}$

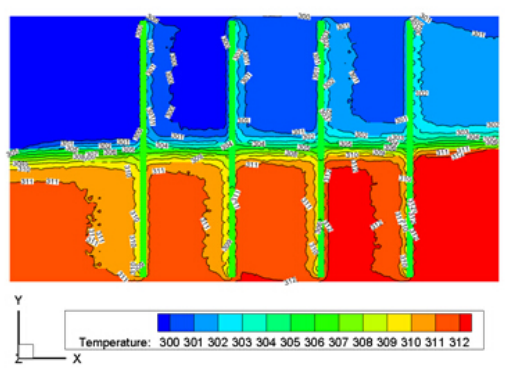

Air velocity $=0.1 \mathrm{~m} / \mathrm{s}$

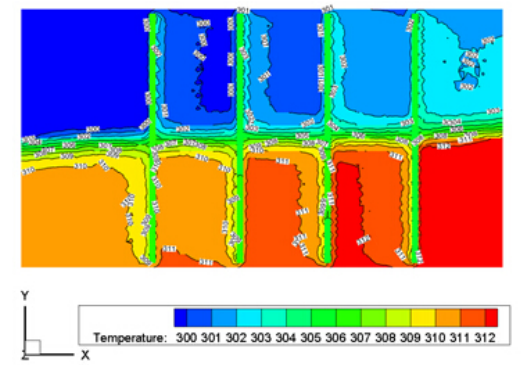

Air velocity $=0.06 \mathrm{~m} / \mathrm{s}$

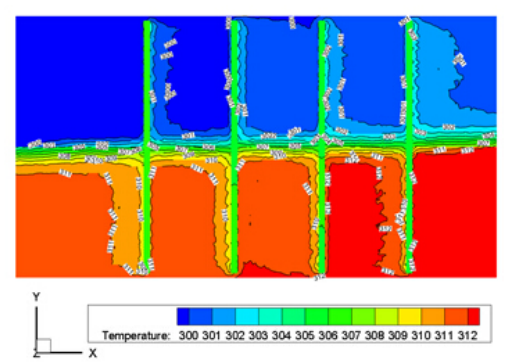

Air velocity $=0.12 \mathrm{~m} / \mathrm{s}$

Fig.4.Temperature diagram of $\mathrm{Z}=0$ section at different air velocity

It is the temperature distribution in the heat exchanger at different air velocity as shown in Fig.3.The temperature change of the hot and cold air in the heat exchanger is seen from the isothermal surface under the heat pipes which maintain a triangular arrangement of cross row. The temperature difference between air inlet and outlet is decreased, and the heat transfer effect of the baffles obviously. Fig.4.shows the temperature chart on $\mathrm{Z}=0$ section in different conditions. There is a significant phenomenon of heat transfer at low air velocity. When the air velocity is increased, the temperature field of the whole heat exchanger can be seen more clearly. 

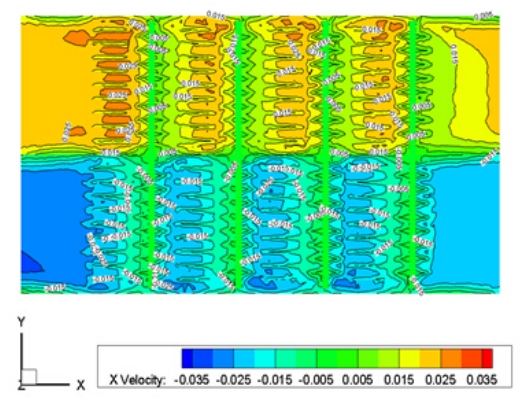

Air velocity $=0.02 \mathrm{~m} / \mathrm{s}$

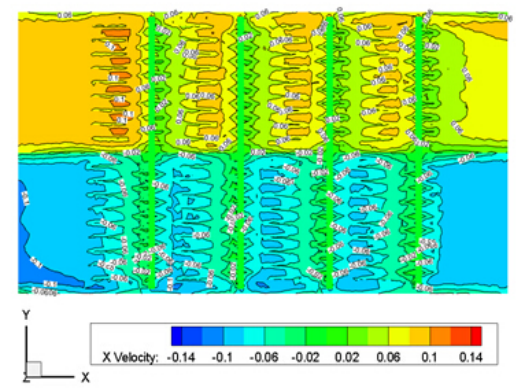

Air velocity $=0.08 \mathrm{~m} / \mathrm{s}$
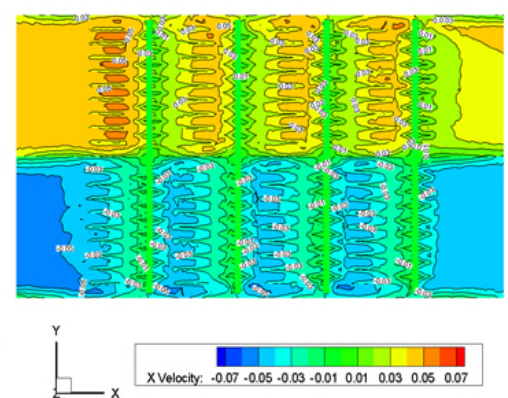

Air velocity $=0.04 \mathrm{~m} / \mathrm{s}$

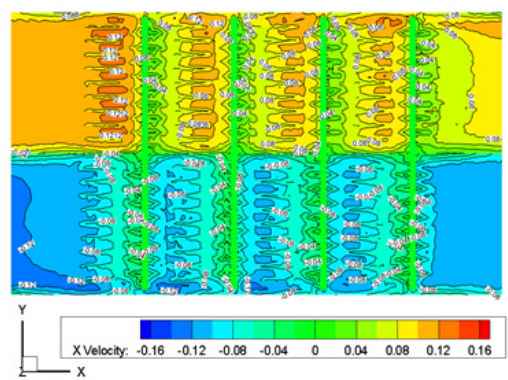

Air velocity $=0.1 \mathrm{~m} / \mathrm{s}$
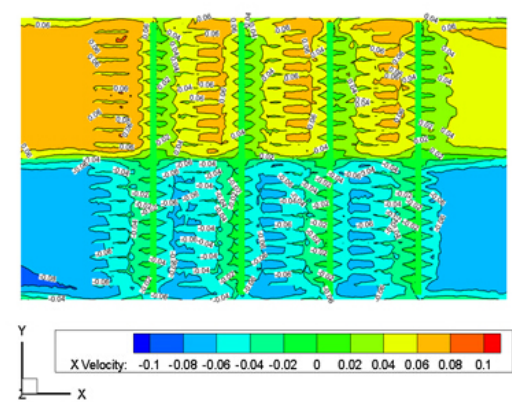

Air velocity $=0.06 \mathrm{~m} / \mathrm{s}$

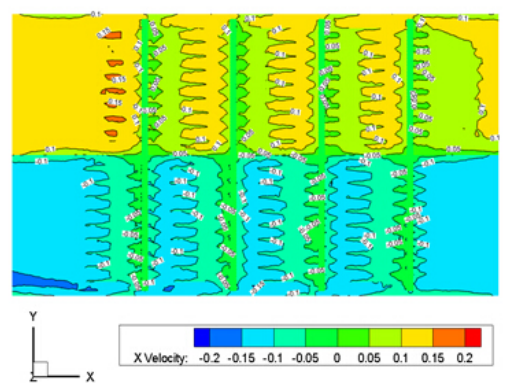

Air velocity $=0.12 \mathrm{~m} / \mathrm{s}$

Fig.5.Velocity diagram of $\mathrm{Z}=0$ section at different air velocity

The velocity distribution in the heat exchanger at different air velocity is shown in Fig.5.The model is based on the positive direction of the $\mathrm{X}$ axis. The cold air flows from left to right. The air in the internal heat exchanger for fork row distribution of heat pipe and flow distribution between staggered fin local acceleration and disturbance in the heat exchanger, while the maximum velocity increased by $65 \%$.
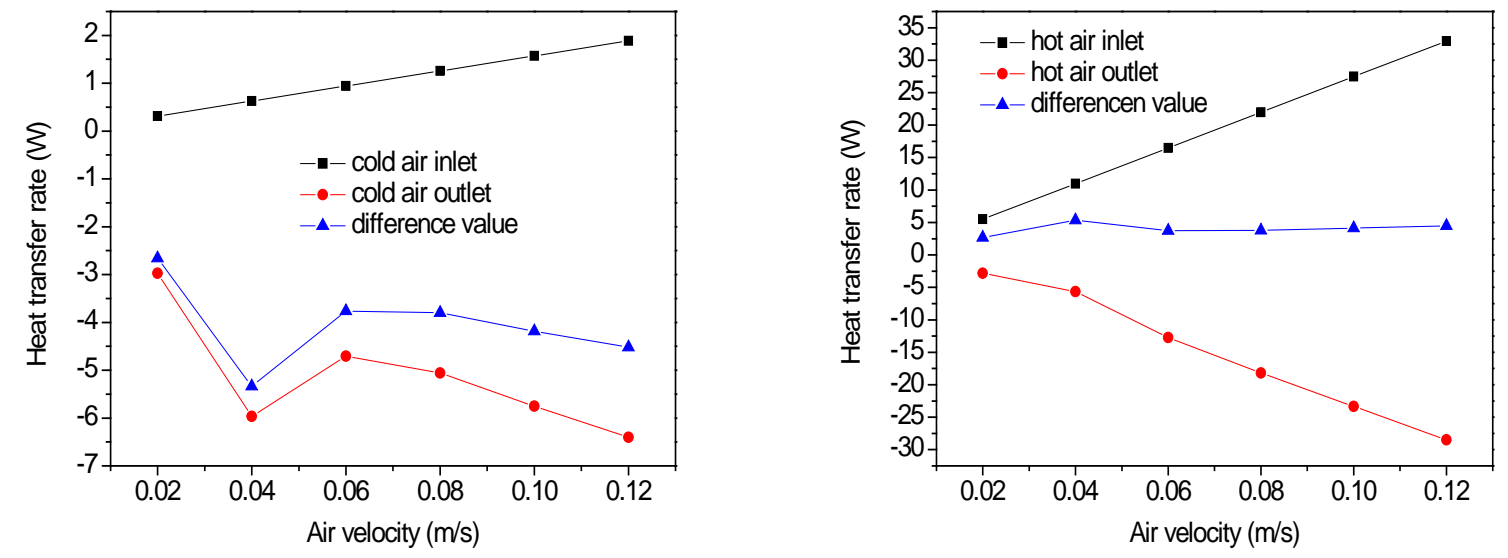

Fig.6. Heat transfer rate of heat pipe heat exchanger

In the simulation process, the heat exchanger can be seen the system. Hot and cold air inflow change counted as a heat exchanger system into heat flow rate, while hot and cold air outflow rate of heat exchanger is counted as the outflow of the system with negative value. The difference is hot and cold air in the flow through the heat exchanger for heat transfer.Fig.6.showsthat with the increase of the ratio of inlet velocity, the heat flow rate of the hot air inlet is also increased. While the difference of heat flow rate of cold air increase with the increase of air velocity, and then decreases. It reaches a maximum heat flux difference when the air velocity is $0.04 \mathrm{~m} / \mathrm{s}$. Comparison of hot air side, in the same $0.04 \mathrm{~m} / \mathrm{s}$ heat flow rate difference reaches a maximum value, and the speed of hot air in the heat exchange effect is the best. 


\section{Conclusions}

(1) Numerical simulation of the heat pipe ventilation heat exchanger with different wind speeds is carried out by the CFD software FLUENT. Study the characteristics of heat transfer efficiency and the distribution of temperature and velocity in the heat exchanger. Comparing the heat transfer performance of heat exchanger with six different wind conditions include $0.02 \mathrm{~m} / \mathrm{s}, 0.04 \mathrm{~m} / \mathrm{s}$, $0.06 \mathrm{~m} / \mathrm{s}, 0.08 \mathrm{~m} / \mathrm{s}, 0.1 \mathrm{~m} / \mathrm{s}$ and $0.12 \mathrm{~m} / \mathrm{s}$.

(2) Temperature difference between air inlet and outlet under the conditions of $0.02 \mathrm{~m} / \mathrm{s}$ and $0.04 \mathrm{~m} / \mathrm{s}$ can reach $7.4 \mathrm{~K}$. The heat recovery rate can reach $52.9 \%$. With the increase of air velocity the temperature difference decreases, and further reduce the velocity the temperature difference no longer increases.

(3) The heat transfer rate of the system can be expressed as the capacity of the cooling air to absorb heat and the heat capacity of the air. Simulation shows in the $0.04 \mathrm{~m} / \mathrm{s}$ conditions the difference of the heat and cold air flow rate is 5.344W.

\section{Acknowledgements}

This work was financially supported by the National Natural Science Foundation of China (Grant No.51276055) and the Hebei Applied Basic Research Program of China (Grant No. 13964503D).

\section{References}

[1] Z.H. Liu, L. Jin, X.H. Wang, P.H. Li, X.M. Yang, Miniature ventilating device with heat pipe heat exchanger applied in laboratory, Heating Ventilating and Air Conditioning. 40 (2012) 10-12.

[2] K.P. Yang, Y.H. Dian, Y.Y. Zhao, J.R. Liu, J.W. Yu, Experimental investigation of heat recovery with thermosyphon heat exchanger, Chem. Eng. (New York).37 (2009) 17-20.

[3] S.M. Sun, H. Zhang, Analysis of CFD simulation with experiment of heat transfer and pressure drop for heat pipe heat exchanger, Journal of Nanjing University of Technology.26(2004)62-66.

[4] S. Tundee, P. Terdtoon, P. Sakulchangsatjatai, R. Singh, A. Akbarzadeh, Heat extraction from salinity-gradient solar ponds using heat pipe heat exchangers, Solar Eenrgy.84(2010)1706-1716.

[5] E.G. Jung, J.H. Boo, Thermal analytical model of latent thermal storage with heat pipe heat exchanger for concentrated solar power, Solar Energy. 102(2014)318-332.

[6] K. Kerrigan, H. Jouhara, G.E. O’Donnell, A.J. Robinson, Heat pipe-based radiator for low grade geothermal energy conversion in domestic space heating, Simulation modeling practice and theory.19(2011)1154-1163.

[7] D.D. Zhu, D. Yan, Z. Li, Modeling and applications of annual energy-using simulation module of separated heat pipe heat exchanger, Energy and Buildings. 57 (2013) 26-33.

[8] S.N. Kazi, G.G. Duffy, X.D. Chen, Validation of heat transfer date for fiber suspensions in coaxial pipe heat exchangers, Exp. Therm Fluid Sci.38(2012)210-222.

[9] Z. Zhang, Y.M. Ding, C.F. Guan, H. Yan, W.M. Yang, Heat transfer enhancement in doublepipe heat exchanger by means of rotor-assembled strands, Chem. Eng. Process. 60(2012)26-33.

[10] H. Jouhara, R. Meskimmon, Experimental investigation of wraparound loop heat pipe heat exchanger used in energy efficient air handling unit, Energy. 35(2010)4592-4599.

[11] F. Yang, X.G. Yuan, G.P. Lin, Waste heat recovery using heat pipe heat exchanger for heating automobile using exhaust gas, Appl. Therm. Eng. 23(2003)367-372.

[12] Y.H. Yau, M. Ahmadzadehtalatapeh, A review on the application of horizontal heat pipe heat exchangers in air conditioning systems in the tropics, Appl. Therm. Eng. 30(2010)77-84. 